modern text-books. I have employed it for years with adrantages hardly to be exaggerated. I venture now to present it to the consideration of those employed in the surgery of the present war.

I am, Sir, yours faithfully,

A. Marmaduke Sheitud,

August 14th, 1916. Consulting Surgeon to St. George's Hospital.

\section{THE PSYCHO-PATHOLOGY OF WAR NEUROSES.}

To the Editor of THE LANCET.

StR,-Captain M. D. Eder's article on this subject was very interesting to read. But are his conclusions sound? All science is based on accurate observation. Where I can test Captain Eder's statements it seems very probable that he has made an inaccurate observation. In Case 7 there is a young man whose bent is towards ships and ship-building. He has obviously been often on the bridge of a ship. Yet Captain Eder reports him as saying, "I ..... rang down full speed ahead." Now, that is what Captain Eder probably thinks is said by sailors, but it is not: "full steam ahead" is what is seen on every ship's telegraph. So it seems very likely to me that Captain Eder has allowed his preconceptions to distort the accuracy of his observations. And if it is so in this case it is probably so in others.

I am, Sir, yours faithfully,

G. Burton-Brown, M.D.

Harston, Sidmouth, A ugust 14th, 1916.

\section{CHINESE TOE-ROT AND FOOT-TETTER.}

\section{To the Editor of THE LANCET.}

StR,-In your issue of June 10th (p. 1200) occurs a short note on "Chinese Toe-Rot." A condition similar to that described is fairly common in Nigeria, and presumably in most tropical countries, but we do not consider that it need be as intractable as indicated in your note. Treatment with various antiseptics and dusting powders as a rule alleviates but does not cure.

The method we advise, based, clinically only, on the fact that the organisms appear to flourish in an acid medium, is usually much more rapidly effective, and consists merely in the repeated application of an antiseptic ointment rendered alkaline in some convenient way, e.g., by adding $5 \mathrm{gr}$. of sod. bicarb. to an ounce of ung. hyd. nit. dil. We have seen a case that had withstood three years' treatment with sulphur or iodine and various antiseptic dusting-powders yield to the treatment indicated within three or four weeks.

We are, Sir, yours faithfully

J. McF. Pollard, M.D. Lond., West African Medical Staff.

J. R. L. Johnston, M.B., B.S. Lond., D.T.M. and H. Camb. West African Medical Staff.

Zungeru, Northern Nigeria, July 10th, 1916

\section{ALIMENTARY REST IN DIABETES.}

To the Editor of THE LANCET.

SIR,-Dr. O. Leyton's letter in THE LANCET of July 8th, $I$ really think, is somewhat captious. The article criticised stated that Guelpa's theory was not generally accepted, and described Allen's method as a "decided advance," which is hardly doing Allen "very scant justice." I was present at the debate. It was generally agreed that mild cases in later life usually respond rapidly to some such method of fasting. In the more severe cases the urine may be freed from sugar temporarily, but sometimes the general well-being of the patient suffers, though even in these severer cases modified fasting will probably be very useful. So far I am in accord with your editorial views. But if Dr. Leyton will turn to the official record of that debate he will find that of the four speakers who followed him, three made statements to that effect. Dr. Spriggs said: "I am inclined to think that in treating a chronic disease it is of importance to maintain the patient in such a state of nutrition that he can work and can enjoy himself." Dr. Ryffel said of his cases that "three were severe, in whom considerable difficulty was experienced in preventing the recurrence of sugar when food was given, so much so that it appeared a better plan to regulate the acetonuria by periodical starvation and not to aim at complete elimination of glycosuria." Dr. Cammidge said : "The dangerous increase in the acidosis, \&c., observed by Stillman in some 10 per cent. of his cases while undergoing Allen's treatment points to there being limitations to the usefulness of the method."-I am, Sir, yours faithfully,

August 11th, 1916.

M.D.

\section{THE EFFECTS OF TRI-NITRO-TOLUENE ON WOMEN WORKERS.}

To the Editor of $\mathrm{TH} \mathrm{I}$ L $\mathrm{A}$ NOET.

SIR,-The observations by Dr. Agnes LivingstoneLearmonth and Dr. Barbara M. Cunningham in your issue of August 12th are interesting as a contribution to the study of T.N.T. poisoning, and prompt these questions: 1 . What methods were adopted for selecting the workers? 2 . How many applicants were rejected? 3 . What are the homes like? 4. How many are unable to take milk, eggs, or cheese, the great lime-bearing foods? 5. Are many of them fond of vinegar, lemons, and acid fruits? 6. What is the state of the teeth?

The writers emphasise the value of cleanliness with what seems but little regard for circumstances. How can working women afford to change constantly their underclothing? Among a class where, when teeth are bad, the cavities are stopped with bread, it is not surprising that underclothes should not be changed. It is here that social workers find an impasse, which can be surmounted only when priests and parsons realise that their responsibility begins in this life, or, to put it more plainly, until they take a more active share in the social work of their people, an example that is set them by the Rabbi of the Hebrew community.

I am, Sir, yours faithfully,

Swansea, August 14th, $1916 . \quad$ G. ARBOUR STEPHENS.

\section{(19bituman.}

\section{MORTON ALFRED SMALE, M.R.C.S. ENG., L.S.A.,} L.D.S.,

CONSUXTING SURGEON-DENTIST, ST. MARX'S HOSPITAL, ETC.

THE death of $\mathrm{Mr}$. Morton Smale in the midst of his activities, at the age of 69 , is a serious loss to the dental branch of the profession of surgery. During the 40 years that have elapsed since he first qualified there is hardly any post of responsibility in the world of dentistry which he has not occupied. We say hardly any, because he never was President of the Odontological Society, neither was he President of the British Dental Association, but it is understood that he refused both these honours.

Morton Smale received his medical education at St. Mary's Hospital, where he afterwards became dental surgeon, having previously served in that capacity at the West London Hospital. He was medical tutor at the Dental Hospital of London, and in 1883 succeeded Mr. Francis Ken Underwood as dean of that institution, a post which he occupied with conspicuous success for 20 years. During that period he effected great changes in the hospital. $\mathrm{He}$ was the guiding spirit in the removal of the hospital from its original site to the present building, and bore no small part in the task of raising the necessary funds. In this difficult enterprise he was greatly assisted by his brother, Mr. William Smale, and very loyally supported both in sharing the work and subscribing the money by the then staff. During his deanship the Dental Hospital of London received the title of Royal. Another great work, costing many months to arrange and many years' constant daily supervision, was the formation, in the face of much opposition, of the appliance department of the hospital. This scheme was planned in 1889 by $\mathbf{M r}$. Morton Smale, Mr. David Hepburn, and Mr. A. S. Underwood. It was the first attempt to deal with the problem of supplying artificial teeth to suitable poor cases, a small fixed sum being demanded towards current expenses. This initiative was subsequently followed by most dental hospitals in the kingdom.

Mr. Smale's connexion with the Royal College of Surgeons of England was long and intimate. In 1886 he induced the Council of the College to allow a part or the whole of the three years' course of instruction in mechanical dentistry to be taken before registration. In 1889 he was appointed to 